\section{Cold and Hot}

\author{
M. Castillo, Editor-in-Chief
}

M ost healthy human beings maintain a core temperature of $37.0^{\circ} \mathrm{C}\left(98.6^{\circ} \mathrm{F}\right)$ regardless of surrounding environmental conditions. Of course, our temperature normally varies slightly throughout the day and night, and this depends on when, how, and where one measures it. Normal human temperature fluctuations tend to be of about $0.5^{\circ} \mathrm{C}$ up or down. A healthy human being is said to be "normothermic" or "euthermic." ${ }^{1}$ Our temperature fluctuates with the circadian cycle as in all other living organisms (circadian rhythms occur in 24-hour cycles [circa = around and dian $=$ day]), and in this way, our bodies can keep track of the duration of normal days over our life span. ${ }^{2}$

The circadian clock is regulated mostly by daylight, and when in dark and/or cold environments, organisms compensate by altering their temperatures. Retinal stimulation by daylight is directly transmitted to the suprachiasmatic nuclei in the hypothalamus, which regulates temperature. ${ }^{3}$ When our temperature increases, hypothalamic neurons induce sweating and cutaneous vasodilation to dissipate heat. When we get cold, the hypothalamus does the opposite and induces shivering that increases heat production. Thirst is also controlled by the hypothalamus, so if our temperature increases, we lose fluids and increase our serum sodium level. Osmotic receptors in the supraoptic nuclei not only tell our cerebral cortex that we need to drink water but stimulate the neurohypophysis to produce an antidiuretic hormone that directly acts on the renal glomeruli, increasing water reabsorption.* Thirst control involves the fore- and hindbrain (especially the area postrema). As serum concentration of sodium increases, phylogenetically ancient brain regions (the cingulate gyrus, third ventricle, orbitofrontal regions, thalami, midbrain, and hypothalamus) become activated on fMRI. ${ }^{4}$

Our temperature is lowest about 2-3 hours before waking up, so it is not surprising that during the wee hours of the night we commonly reach for our covers. Conversely, our temperature is higher in the late afternoon (and this is why fever and malaise peak at this time when sick). Sleep deprivation, even short-term, lowers our body temperature, and I remember feeling cold on the days after I had been up all night as an intern and sitting in the sun to warm up. The endogenous substances that most affect our circadian cycle are hormones, and temperature variations induced by them have been used to predict ovulation during the normal menstrual cycle (also called the circamensal cycle $[$ circa $=$ around, mensa $=$ month]). Contraceptives suppress the circamensal cycle and result in elevations of temperature of about $0.5^{\circ} \mathrm{C}$ throughout the entire month.

\footnotetext{
* NB: I recommend the following wonderful review dealing with issues related to thirst: McKinley MJ, Johnson AK. The physiologic regulation of thirst and fluid intake. News Physiol Sci 2004;19:1-6.

http://dx.doi.org/10.3174/ajnr.A3576
}

As mentioned previously, our temperature is highest in the afternoons when it reaches about $37.7^{\circ} \mathrm{C}$. Anything above this threshold is considered as fever. Under normal conditions, our bodies are capable of dissipating heat to just about $40.0^{\circ} \mathrm{C}$, and above this threshold, one enters the state of hyperthermia and starts to develop severe headache and altered mental status. Severe and prolonged hyperthermia results in a heat stroke. Neurologic abnormalities induced by heat stroke involve the brain (especially the basal ganglia and thalami), cerebellum, anterior horn cells in the spinal cord, and peripheral nerves. ${ }^{5}$ Hemorrhages in the external capsule and medial thalami may occur. In the cerebellum, the Purkinje cells are especially sensitive to heat, and patients with hyperthermia may later develop chronic cerebellar atrophy. ${ }^{6}$

The opposite extreme is hypothermia, which is defined as a drop of $2.0^{\circ} \mathrm{C}$ in body temperature (we begin to shiver at about $36.0^{\circ} \mathrm{C}$ ). Hypothermia is generally due to exposure to inclement weather or is induced for medical procedures. Protective hypothermia is mainly used for the treatment of neonatal encephalopathy, cardiac arrest, neurogenic fever, and more recently brain and spinal cord trauma. For these conditions, the goal is to reach $33.0^{\circ} \mathrm{C}$, with the hope that slowing cellular metabolism will be neuroprotective. Lower temperatures inhibit the influx of ions (noticeably calcium) into cells, avoid oxidative stress, decrease free radical production, and, finally, prevent apoptosis. Cooling may be achieved via invasive means (catheters that pump cold saline solution into veins) or noninvasively (water blankets and cool caps that contain crylon gel at $-30^{\circ} \mathrm{C}$ ). Cool caps are used for neonatal encephalopathy but also for less serious problems such as alopecia induced by chemotherapy (in the latter, the cold results in decreased scalp blood flow protecting the hair follicles). ${ }^{7}$ In an intriguing new article published in the American Journal of Neuroradiology (AJNR), the authors used catheters placed in the subarachnoid space of swine to cool down the spinal cord without cooling the entire body. ${ }^{8}$ This and other similar experiments have shown that the technique is feasible and may spare complications induced by whole-body hypothermia.

We humans detect temperature changes due to stimulation of our peripheral thermoreceptors found in the skin and mucosa. These receptors are nerve fibers that work in tandem-that is, when exposed to cold, delta fast-speed fibers fire more than the slower C-fibers that are sensitive to heat, but both work simultaneously and the perception of temperature depends on the proportion of each type of fiber that is activated. These fibers enter the spinal cord and ascend in the spinothalamic tracts to the posterolateral thalamic nuclei. From there, the stimuli reach a collection of organs and nuclei best known as the hypothalamus.

Time for an anecdote: Years ago the Chief of Neurosurgery and I decided to seal a CSF leak due to a previous transsphenoidal pituitary adenoma resection with liquid fibrin glue. Under CT guidance, we proceeded to place a needle through the nose of the patient into the breached sellar floor and started injecting the glue. The patient immediately became severely hypothermic, and a 
control CT showed that our needle was too deep and the glue had reached the hypothalamus. The patient spent a week in the intensive care unit, and though he completely recovered, it still gives me goose bumps to think about it.

There is no consensus about the most comfortable temperature. The way we perceive temperature has a lot to do with the humidity accompanying it. For example, if the humidity is $0 \%$, $24^{\circ} \mathrm{C}$ will feel like $21^{\circ} \mathrm{C}$, while with a $100 \%$ humidity, $24^{\circ} \mathrm{C}$ will feel like $27^{\circ} \mathrm{C}$. The most comfortable humidity levels are between $40 \%$ and 50\% (levels also said to prevent upper respiratory tract infections). In places with extreme outside temperature variations, it is recommended that inside temperatures be kept at $21^{\circ}-23^{\circ} \mathrm{C}$ $\left(69^{\circ}-73^{\circ} \mathrm{F}\right) .^{9}$ In the United States, the Occupational Safety and Health Administration recommends a range of $20.5^{\circ}-24.5^{\circ} \mathrm{C}$ $\left(68^{\circ}-76^{\circ} \mathrm{F}\right)$ and humidity between $20 \%$ and $60 \%$ at workplaces. ${ }^{10}$ Another anecdote: Upon arriving in Panama City, my colleague and friend, Dr Ilka Guerrero asked me if I had brought a sweater because the city was about the coldest place on earth. After entering my hotel, I understood what she meant. Air conditioning thermostats were kept at $16^{\circ} \mathrm{C}\left(62^{\circ} \mathrm{F}\right)$. Those of us who grew up elsewhere in warmer latitudes never cease to be amazed by how cold buildings are kept in the United States (they are even colder in the United Kingdom where regulations dictate temperature at the workplace be "reasonable" — that is, $16^{\circ} \mathrm{C}\left(61^{\circ} \mathrm{F}\right) !^{11}$

Cold inside buildings is a luxury, and it has been documented that the most expensive stores (Hermes, $20^{\circ} \mathrm{C}$ ) are kept colder than the least expensive ones (Old Navy, $27^{\circ} \mathrm{C}$ ). ${ }^{12}$ Apparently colder spaces encourage us to buy more and also save electricity. We radiologists must work in cold environments because computers and monitors (not to forget the view boxes of the past) generate a lot of heat and reading rooms can only be kept comfortable by lowering the thermostat. Work productivity is better at stable and slightly lower temperatures ${ }^{13}$ but colder temperatures are uncomfortable and the New York Public Library allows their workers to accrue compensatory time when its temperature drops below $20^{\circ} \mathrm{C}\left(68^{\circ} \mathrm{F}\right)$.

It is a common belief that heavier individuals are more sensitive to heat (and conversely will feel cold to the touch), while skinny ones are sensitive to cold (but will be hot to the touch). Subcutaneous fat serves as an insulator, but women, who as a general rule have more of it, are more sensitive to cold than men. ${ }^{14}$ Malnourished individuals with little fat may experience hypothermia in temperatures of only $15^{\circ}-18^{\circ} \mathrm{C} .{ }^{15}$ An intriguing observation is that hot and cold result in nearly identical brain responses. (When ice first arrived in Maconda in Garcia Marquez's One Hundred Years of Solitude, people could not tell if it was hot or cold.) With fMRI, the response to noxious hot and cold stimulation was studied, and it was shown that extreme temperatures both activated similar networks. ${ }^{16}$ While this study and others confirm the activation of unified neural networks for different intensities of temperature, other studies show that the perception of pleasantness or unpleasantness associated with temperature changes occurs in different brain regions. ${ }^{17}$ More or less neuronal firing in these areas occurs as temperature changes.

Our feeling of well-being is tied to what we believe is a comfortable temperature, and some of our activities are immediately associated with temperature. Reading by a source of warmth such as a fireplace comes to mind except when it comes to AJNR, which I think can be read when it is cold or hot.

\section{REFERENCES}

1. Human body temperature. http://en.wikipedia.org/wiki/Human_body_ temperature. Accessed February 21, 2013

2. Circadian rhythm. http://en.wikipedia.org/wiki/Circadian_rhythm. Accessed February 21, 2013

3. Hypothalamus. http://www.neuroanatomy.wisc.edu/coursebook/ neuro2\%282\%29.pdf. Accessed February 21, 2013

4. Denton D, Shade R, Zamarippa F, et al. Neuroimaging of genesis and satiation of thirst and the interceptor-driven theory of origins of primary consciousness. Proc Natl Acad Sci U S A 1999;96:5304-09

5. McLaughlin CT, Kane AG, Auber AE. MR imaging of heat stroke: external capsule and thalamic $\mathrm{T} 1$ shortening and cerebellar injury. AJNR Am J Neuroradiol 2003;24:1372-75

6. Albukrek D, Bakon M, Moran DS, et al. Heat stroke-induced cerebellar atrophy: clinical course-CT and MR findings. Neuroradiology 1997;39:195-97

7. Hypothermia cap. http://en.wikipedia.org/wiki/Hypothermia_cap. Accessed February 21, 2013

8. Purdy PD, Navakovic RL, Giles BP, et al. Spinal cord hypothermia without systemic hypothermia. AJNR Am J Neuroradiol 2013; 34:252-56

9. Canadian Centre for Occupational Health and Safety. Thermal comfort for office work. http://www.ccohs.ca/oshanswers/phys_agents/ thermal_comfort.html. Accessed February 21, 2013

10. United States Department of Labor. Office temperature/humidity. http://www.osha.gov/pls/oshaweb/owadisp.show_document?p_ table $=$ INTERPRETATIONS\&p_id $=24602$. Accessed February 21, 2013

11. Buettner R. In New York City, a chilly library has its rewards. The New York Times. http://www.nytimes.com/2010/01/12/nyregion/12libraries. html?_r $=0$. Accessed March 11, 2013

12. Salkin A. Shivering for luxury. The New York Times. June 26, 2005. http://www.nytimes.com/2005/06/26/fashion/sundaystyles/26air. html. Accessed March 11, 2013

13. Salmon R. Air-conditioning made this debate possible. The New York Times. http://www.nytimes.com/roomfordebate/2012/06/21/ should-air-conditioning-go-global-or-be-rationed-away/airconditioning-made-this-debate-possible. Accessed March 11, 2013

14. Fillingim RB, Maixner W, Kincaid S, et al. Sex differences in temporal summation but not sensory-discriminative processing of thermal pain. Pain 1998;75:121-27

15. Human biological adaptability: an overview. http://anthro.palomar. edu/adapt/adapt_1.htm. Accessed February 21, 2013

16. Tracey I, Becerra L, Chang I, et al. Noxious hot and cold stimulation produce common patterns of brain activation in humans: a functional magnetic resonance imaging study. Neurosci Lett 2000; 288:159-62

17. Rolls E, Graberhorst F, Parris BA. Warm pleasant feelings in the brain. Neuroimage 2008;41:1504-13

\section{EDITORIAL}

\section{Stretch-Resistant Coils for Intracranial Aneurysms: One Step Forward or Two Steps Back?}

W.J. van Rooij
M. Sluzewski

ndovascular treatment of cerebral aneurysms was boosted by

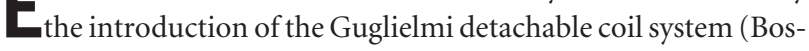
ton Scientific, Natick, Massachusetts) in 1991. The concept of

http://dx.doi.org/10.3174/ajnr.A3727 